\title{
On consultation
}

\author{
JUliA NelkI, Senior Registrar in Child and Adolescent Psychiatry, The Tavistock Clinic, \\ London NW3
}

Consultation is a term that can have many different meanings. In this paper, it is used in the sense that Caplan (1964) defines as mental health consultation, to describe the interaction between a consultee and consultant who meet to facilitate some area of mental health work in which the consultee is involved. By working with workers instead of directly with clients, the consultant aims to offer a service to a greater number of people than would otherwise be possible and to have a preventive role with earlier detection and management of mental health problems.

I have been meeting with the staff of a children's day nursery fortnightly for 18 months and feel that I have only just begun to be a consultant to them by which I mean "enabling the staff to reflect on their work and understand the group and organisational factors that interfere with their primary task" (Britton, 1976) which in this case is to help the children in the nursery.

The process of arriving at a stage of consultation with the staff has been one of constantly negotiating a balance between being accepted into the nursery, being accessible and approachable while also being able to maintain a certain distance, to give an overview and help the group stay with the task. Obholzer (1987) says that "in order for the consultant to operate effectively he needs to be an outsider, to have an independent base and to have a style in which he enables the institution to find its own solutions in the climate of consultation created by him or her as opposed to solutions being suggested or imposed from outside".

The nursery had not had a consultant before and together we have developed a style that has enabled us more or less to stick to the task we set ourselves. Supervision has been invaluable for there were many temptations diverting us all from our task. The staff have wanted me to give talks, see children, discuss policy. I have wanted to join in with the day to day work, play with the children, shout at the parents, join them on the picket line. I have shared anger and concern at threats to the work - the hopelessness and the helplessness of the staff and several times I have wanted to give up. Keeping the task in mind has prevented me from being irretrievably diverted and the result has been fruitful, for we are now a working group looking together at how the children's difficult behaviour can at times reflect difficulties in the staff group and how looking at staff relationships can help the children.

I will describe first the setting, then the initial stages of the work, concluding with a summary of the development up to the present time.

\section{Setting}

The nursery is funded and managed by social services and takes up to 50 children, a mixture of social classes: families where both parents work outside the home and those in difficult emotional and financial situations. Children aged from 9 months to 5 years attend and the Centre is open from 7.30 a.m. until 6.00 p.m., on all days except Bank Holidays.

There are up to 13 staff - an organiser, deputy and child care workers - although they have not in the time that I have been there had their full quota. Each child has a key worker and the children are in six groups, each run by two workers.

As well as internal supervision, they have a fortnightly policy meeting alternating with the group here described. There is a high degree of absenteeism and a high staff turnover. The present political climate has demoralised the staff considerably. More children are taken in without adequate preparation: parents who have always had to pay a token fee can no longer afford the higher fees and many children are having to leave. Some of the staff are looking for more secure employment.

The Centre is a new building, decorated with children's drawings and playthings and has a pleasant atmosphere. The staff have always been friendly and welcoming to me, even in their most difficult times, and when resenting my freedom to leave and the salary I get.

\section{Initial negotiations}

I worked with the deputy organiser in another setting over a child who had been sexually abused. It was a distressing case, stirring up a lot of feelings in the nursery. A few months later I was contacted by the deputy to ask whether I could offer a regular consultation "to support the staff". Both in a wish to make good over the difficult handling of the child sexual abuse case and because of my own senior 
registrar training needs, I agreed to explore it further. I met the organiser and deputy to discuss feasibility and agreed that I would write to their manager and meet the staff group to discuss it further. Permission was given.

In the initial staff meeting there was a superficial friendliness with some underlying suspicion-who was I and what was I really there for? They expressed both a desire for an expert to tell them what to do and a feeling that I could not, as an outsider, possibly understand their situation; feelings which recurred throughout our meetings.

It was clearly a transitional time in the nursery with many changes of staff. As the changes have become fewer, the group has become more coherent. Together we drew up a contract-which was reviewed and revised at intervals. We decided to begin by looking at the behaviour of individual children and to try to understand it in the context of the child's relationships at home and in the nursery. From here, we agreed to look at staff relationships and how these reflected and were affected by the children's behaviour and how they could be improved.

\section{Development}

From an individual child centred approach, the group began to look at staff relationships in the context of the work in the institution. I, as consultant, provided a bridge between the children and the staff helping them to look at how their professional and personal views of themselves affect and are affected by, the children in the nursery.

The group had a chaotic start with continual interruptions, few people attending and some never coming. Out of this developed a coherent group that began on time with everyone coming to some meetings and most participating. A "Do Not Disturb" notice on the door became a regular feature and a notice asking parents to bring children in late on that day if possible.

Three areas have been felt important in this process:

(a) individual alliances/engagement with the group

(b) dealing with discontinuity

(c) style of working.

\section{Individual alliances/engagement with the group}

At the beginning, I had most contact with the deputy who often talked to me after the group with requests that I give talks or see children. The staff began to see me as "in league" with him, having been called in by him to sort them out, perhaps even showing him the notes I made - analysing each of them and giving him the feedback. I avoided further alliances and discussed any requests with the group as a whole. I said how uncomfortable it can be to have an outsider watching the way they work and how the wish for me to do something else could distract us all from our task. This led to a shift and to them seeing me differently. In explaining my role to newcomers they would say "She's there to bounce ideas off, not give advice", "Someone who doesn't take sides" and the group is described as "Somewhere where everyone can feel they can equally participate".

However, it continued to feel like a tightrope - the wariness remained, new people arrived - I would feel uneasy and the need to make individual contacts but was careful to do it in a way that gave me access to the group rather than an avoidance of it.

\section{Dealing with discontinuity}

In the initial stages, there was disillusionment. From enthusiasm they sank back in despair for I did not have magic answers. They said there was no time for meetings like ours, there was too much else to do. I felt I was failing - what could a group possibly offer when their work was so hard? My experience of frustration, feeling useless, undervalued and unappreciated was identical with and mirrored day to day experience in the nursery - for the staff felt this in relation to the children's parents and to the local authority. Acknowledging this with them, being reminded myself of the benefits and the discomfort of having time to think, helped me to value the group more and then enabled me to help them to value it too, which they began to do.

Discontinuity in our meeting was unavoidable. For everyone to be able to attend some of the time, there had to be different people at each meeting. We agreed to make each meeting self contained in its own right which helped. Although discontinuity was a feature of nursery life, it was also a way of avoiding the pain which the constant making and breaking of attachments that accompanies this work involves. Losses were not acknowledged-staff came and went, children came and left - I often heard about it after the event. The wish to act rather than think became compelling - for them and at times for me.

Before one session, the organiser told me that she was going to leave but had not been able to tell the rest of the staff - she had been withdrawing slowly so that her departure would not be so noticeable as she did not want to upset them. I suggested she talk about it in the group which she then did, realising that it was the discomfort of telling them she wanted to avoid, feeling that she was "leaving the sinking ship". After initial support and praise the group focused their attention on one of the children, who was "winding them all up". Should they set firm limits on him - but he had such a free spirit - would it 
destroy his creativity? I linked this with their feeling at the organiser for leaving - being free to do what she wanted, not limited by the constraints of the nursery. Should they support her or hold her back? They returned to the child - he'd be all right because he got a lot of attention for what he did. I said people left behind were feeling ignored and resentful and that it was the ones who left who got the attention. They talked about how hard their work was-and someone said "Some have short sentences, others are lifers".

At another meeting when I heard about yet another child who shortly before he was due to leave to go to school had become very disruptive and uncontainable so that he was abruptly taken away, I wondered if it was a pattern, a way to avoid the pain of leaving. We had talked about staff leaving, and I asked what that was like for the children. "A lot of new input. It's good for them", was the initial response and then that it was too painful to think of them being upset and easier not to. One worker said that talking about children and staff leaving reminded her of her own losses and when I said that it would do that for the children too, she said quickly, "They don't have long memories do they?", without waiting for an answer. Concern was then expressed about the consequences for the children of all these changes. The staff oscillated between extremes from feeling that whatever they did had no effect, to feeling that they could cause irreparable damage. We talked about a less extreme possibility, that dealing with losses could help with future and past experiences. They decided to invite the child back for a proper farewell.

\section{Style of working}

I have shared my feelings in the group and used my experience to understand how children may feel in the nursery. I have fed this back to them and acted as a mirror, reflecting back what I have seen. I have also asked questions to help staff think about their relationships with each other. I have tended to bring the focus back to them in their work more than to their relationship with me and the staff group began to look at relationships with each other, accepting this now as a task of the group. More direct interpretations were made though it became necessary to focus on the group as a work group, not a therapy group and to make sure that the children were always kept in mind.

When looking at styles of working for the staff with the children, the organisers with the staff and the group with me, similar themes have emerged. Two models have been compared: that of firmness, control, being told what to do and the other, of individual expression, creativity and personal responsibility.
Although those who took firm control and a directive position were heavily criticised, it emerged that there was a definite wish for this to continue, and for personal responsibility to be avoided. Many of the staff had been child care workers for several years, never applying for promotion. Their view of themselves as powerless, abused victims went alongside a determination to stay in a one down position, a wish to be martyrs, heroes and indispensable.

They are at present negotiating what can be said and what cannot - how much they trust each other and how much they trust me. Someone said recently, "It's harder now talking about us. It was easier before talking about the children or someone else. It's too dangerous to talk about us". Others disagree, feeling that honesty and openness with each other will benefit the children. My impression is that the barriers erected to deal with the pain inherent in the work are manifest in the staff's relationships with each other and lead to dissatisfaction and friction in their working relationships.

\section{Conclusion}

I have recognised three stages in the process of becoming a consultant:

(a) of being in there with the staff experiencing the chaos, pain and abuse; switching off and wanting to leave; feeling hopeless and unwanted

(b) of my being able to think and to value what they and $I$ both have to offer and thereby being able to create a space and safe structure in which thinking is possible

(c) from here, we have reached a stage where the staff are able to think and reflect on their work and to begin to trust each other.

I have learned a lot. The staff have been supportive and tolerant and we have learned from each other. In particular:

(a) the fine balance between action to avoid thought and effective action to protect work as in giving and being given time to think as well as being able to act and unite when necessary. The dire effect of the cuts may have helped to unite the staff in action to combat them;

(b) the importance of a leadership that allows creativity and personal authority without either denying the particular role of a leader or abusing the power such a position affords.

This will affect how I work as a consultant child psychiatrist enabling me, I hope, to take the responsibility and authority such a position offers without denying or restricting other people's creativity. 
I respect the staff a great deal and am grateful to them for allowing me to share their experiences with them.

\section{Acknowledgements}

Many thanks to all the staff at the nursery and to Dr Sebastian Kraemer who supervised the work and helped keep me on the right track.

\section{References}

Brrtron, R. (1976) Consultations in Child Care. Tavistock Clinic, Document No. EN 1654.

Caplan, G. (1964) Principles of Preventive Psychiatry, London: Tavistock Publications.

OBHOLZER, A. (1987) The Assessment Process in the Work of Consulting to Institutions. Tavistock Clinic Paper No. 70.

\title{
Doctors' attitudes to male homosexuality: a survey
}

\author{
Dinesh Bhugra, Senior Registrar, Maudsley Hospital, Denmark Hill, London SE5
}

The topic of homosexuality has often aroused strong opinions among the public and professionals alike. In a study organised by the journal Modern Medicine in $1969,17,741$ physicians in the USA responded to a questionnaire. Of those who stated their speciality, $8 \%$ were psychiatrists, $26 \%$ general practitioners and $10 \%$ general surgeons. Questions sought opinions on abortion, legalisation of marijuana, legalisation of homosexual practice and other topics; $92 \%$ of psychiatrists $[n 2,041]$ were in favour of legalising homosexual practices. The three specialities least in favour were general practitioners $59 \%$ [ $n$ $6,927$, general surgeons $59 \%$ [ 2,580$]$ and orthopaedic surgeons $58 \%$ [ $n$ 731]. The sample was selfselected and this may have introduced a respondent bias. The data were collected nearly 20 years ago when homosexuality was still seen as a psychiatric illness in the American Psychiatric Association's Diagnostic and Statistical Manuals I and II.

A study in the UK in 1973 by Morris used a postal questionnaire to enquire into the attitudes of 150 general practitioners and 150 psychiatrists selected at random. Psychiatrists were more likely to see homosexuality as inborn with development in infancy; $4 \%$ of general practitioners and $8 \%$ of psychiatrists saw homosexuality as a disease. In 1974 Barr \& Catts in Australia found that $35 \%$ of psychiatrists in their sample saw homosexuality as a neurotic illness, compared to $19 \%$ of psychiatric trainees. Attitudes of doctors to homosexuality may be expected to vary according to age, sex, cultural background, training, specialty, religion, etc. Psychiatry is affected by the cultural milieu within which it is embedded, reflecting the dominant values of the time and place and perhaps tending to challenge social values and practices.
Several studies have demonstrated that homosexuals fear to disclose their sexuality to their doctors (Maurer, 1975; Morton \& McManus, 1986), and that they also tend to feel that the medical profession is less geared towards their needs than to those of heterosexuals (Dardick \& Grady, 1980). Yet problems experienced by male homosexuals are determined in part by public attitudes and doctors are in some respects able to lead public opinion. Therefore it is of interest to inquire into doctors' attitudes towards homosexuality.

\section{The study}

The present study set out to investigate the attitudes of psychiatrists and general practitioners, the two groups most likely to be approached by homosexuals for medical help in issues concerning their sexuality. The study focused on male homosexuality because male homosexuals attract more attention and appear to arouse stronger feelings than female homosexuals.

A questionnaire was designed specifically for the study, though several items had been previously used by other authors. Respondents were asked to quantify their agreement or disagreement with a series of statements on a 5-point scale. The questionnaire was circulated with an explanatory letter and a Freepost envelope for replies to all the psychiatrists and the inceptors in the Midlands division of the Royal College of Psychiatrists [n 510] whose addresses had been obtained through the College. Questionnaires were sent to an equivalent number of general practitioners [GPs] from the same geographical area, randomly selected from Family Practitioner Committee lists. The 'strongly agree' and 'agree' responses were summated as were 'strongly disagree' 